\title{
The Perception of the Teachers Towards Virtual Class and Obstacles During Covid-19 Lockdown Phase
}

\author{
Uttam Sing Rai ${ }^{1}$ \\ Hom Bahadur Basnet ${ }^{2}$
}

\begin{abstract}
Virtual class uses computer software and internet to deliver instruction to the students. This eliminates needs for teachers and students to share the physical classroom. Virtual learning is an emerging educational paradigm which is transforming the way students learn. However, this virgin field of research has not been studied rigorously in the context of Nepal. Considering this, the research was carried out to identify the perception of the teacher of Bhojpur Multiple Campus towards virtual class during COVID-19 lockdown phase. The research adopted quantitative design which is based on the teachers who were involved in virtual teaching during COVID-19 lockdown phase. The study applied non-random purposive sampling process to select the sample for gathering data. The researcher found out that the teachers had the positive perception towards virtual class as 68\% teachers agreed with the statement that virtual class is suitable solution during COVID-19 lockdown phase because it saves time and effort. The study may contribute to the educators and the teachers who are thinking to formulate policy for applying virtual class during luck down phase when pandemic is overwhelmed across the country like Covid-19.
\end{abstract}

Keywords: perception, virtual Class, obstacles, experiences

\section{Introduction}

Virtual teaching or learning is an emerging teaching learning process where the teachers and the students do not share physical classroom and they meet through information and communication technology. They can interact with each other in

\footnotetext{
${ }^{1}$ Mr. Rai (Principal Author) is working as Lecturer at TU, Bhojpur Multiple Campus, Bhojpur, Nepal

${ }^{2} \mathrm{Mr}$. Basnet (Co-Author) is working as Associate Professor at TU, Dhankuta Multiple Campus Dhankuta, Nepal E-mail: hom.basnet@dhmc.tu.edu.np
} 
real time using teleconferencing (audio or desktop video-conferencing) or internet ( Dede, 1996). Virtual teaching or learning is also known as online teaching or learning where the students and the teachers interact with each other through (ICT) technologies through various apps Google meet, Zoom Meeting, Microsoft Team, etc. on their computer, laptop, smart mobile phone, etc.

Virtual learning can cater the educational needs of all segments of the society. Bates, M. W. (1995) stated that virtual learning is more flexible, personal, competence based interactive paradigm for learning with in learning communities. It is an open and collaborative teaching learning process, which depend upon the information and communication technology. It makes available the teaching learning resources and services to the learners for individual study (Morris, 1997). The students and the teachers do not meet personally, although this could happen in virtual setting with synchronous interaction (Dede, 1996).

According to UNESCO (2006), in many developing countries, online learning emerges as profound way of teaching and learning, thus making the ratio of trained teachers towards negative directions. With the advancement and availability of technologies on fingertip (internet connection and IT Supports) in many devel ${ }^{1}$ oping countries, the use of online learning has been increased with great pace (Williams, et.al., 2011). Therefore, it is going through a paradigm shift from the guided independent study to interactive networked multimedia education ( Kirschner, Valcke, \& Sluijsmans, 1999).

However, still some challenges prevail in developing countries. In developing countries, the active and participative students, deemed for interactive type of learning are minute while the teaching and learning through traditional methods are numerous (Andersson, 2009). In the same context, developing countries have least capability to apply modern practices in education.

\section{Impact of COVID-19 on Education and Virtual Class}

According to WHO (2020), first significant outbreak of Coronavirus was recorded in December 2019 from China's 7th most popular city Wuhan. Within a few months, the virus spread to other countries, including Nepal. Although lockdown and social distancing brought positive outcomes, they also led to the immediate closure of educational institutions (Figueiredo, et. al., 2020). These nationwide closures are affecting more than $80 \%$ of young students, adversely affecting their educational activities. Institutions are facing considerable challenges to counteract against these challenges by resorting to distance learning systems (UNESCO, 2020).

Despite the current pandemic hampered the education all over the world, virtual learning and easy access to internet service facilitated the learning system. Schools, colleges, universities and instructors instantly adopted online sources to continue their educational journey through video conferencing application and 
modules (ILO, 2020). As noted by Habes (2019), improved communication technologies mostly facilitated the learning systems as accessibility to Social Media is a useful source of information and communication. Both students and teachers consider online technology as a positive part of their learning system. Even besides online sources, many countries also launched television broadcast to support distance learning during the pandemic (UNHCR, 2020).

Sultan(2020) prioritized that the distance learning, primarily through online system, is a 'paradigm shift in education'. The jammed wheel of education raised certain uncertainties regarding the future of the students, but it also highlighted the significance of the technologies in our lives. In this regard, Muhaisen (2020), also considers online learning as a useful tool to overcome educational challenges. Generally, both the students and teachers are equally responsible to accept online learning which help to continue the learning process as access to education today more convenient through online learning system (Ali, 2019). However, many argue that the current crisis is not the normal shift from formal to informal education rather; it is an educational crisis as well. Thus, if tackled strategically, this urgent shift can bring several positive outcomes for both the students and the instructor ( Adnan,2020).

\section{Virtual Learning during COVID-19 in Nepal}

Nepal officially closed all educational institutions to control the spread of COVID-19 on March 19, 2020. Since March, the pandemic has kept nearly 8 million Nepali students away from their classrooms. The pandemic worsened further education outcomes, increased dropout rates, and left behind the most vulnerable students. In this difficult context, Nepal has placed education at the center of its COVID-19 emergency response and has pursued remote and e-learning.

Ministry of Education (MoE) conducted the classes of Secondary and Basic School of Nepal through Nepal Television and Janata Television during COVID-19 lockdown phase. PABSON had also run the classes of English Medium of Boarding School through Television.

Tribhuvan University (TU) launched different academic programs such as seminar, training, meetings, etc. through different apps like Zoom meeting, MS Team, Google Meet, etc. during COVID-19 lockdown phase. Teachers and students were not familiar with virtual learning before pandemic spread in Nepal though they had heard before little about virtual learning. So COVID-19 created a golden opportunity to the students and teachers to be familiar and habituated with online interaction. The teachers of TU from different faculties conducted the classes of the students through different apps during COVID-19 lockdown phase.

The paradigm of pedagogy shifted from traditional method (i.e. chalk and talk) to ICT based teaching method during COVID-19 lockdown phase. The students got chance to interact with the teachers living in their own residents through virtual mode. The teachers also got the chance to enhance their ability in operating 
ICT tools and virtual teaching. Virtual learning became an alternative solution to overcome the educational crisis during COVID-19 lockdown phase.

\section{Virtual Class in Bhojpur Multiple Campus during COVID-19 Lockdown Phase}

Nationwide lockdown imposed by the government of Nepal impacted the regular classes of Bhojpur Multiple Campus. All physical classes remained closed during COVID-19 lockdown phase in the campus. All the teachers and the students stayed at their home at first for few months. They got quite confused for running classes. When Office of the Rector, TU, took action and ordered to run virtual classes in its affiliated and branch campuses, Bhojpur Campus also initiated virtual class. The campus collected the data of the students who had internet access and electricity. It was found that nearly five percent student of Bachelor had internet access. So, the Campus conducted virtual class only for the students of master degree.

The nationwide lockdown imposed by the government impacted educational field of Bhojpur. The campus and schools remained closed for long time. The students were like the prisoners at their home. The office of Rector of Tribhuvan University initiated the process of virtual learning. It developed and provided e-mail address of the students and teachers who are involved in TU. Rector Office also gave training to the teachers of how to run virtual classes using ICT tools.

Many teachers started to teach their students through virtual mode maintaining social distancing. The students were excited and enthusiastic at virtual classes. The teachers were also excited and interested towards virtual learning. They had interaction a lot in the virtual class. However, in my own observation, all teachers did not have the similar perception towards virtual learning. Some of them had positive responses but some of them started to blame virtual learning negatively. The teachers suffered from many obstacles regarding virtual learning. They did not have enough knowledge and skills in computer. They did not have laptop or computer. They did not have stable internet access and electricity in their house.

Therefore, we have undertaken this study to explore the attitudes of the teachers towards virtual learning during COVID-19 lockdown phase. This study also aims at finding out some obstacles or difficulties faced by the teachers in virtual learning during lockdown period. The following were the objectives of the study:

To examine the perception of the teachers toward virtual class;

To explore the obstacles of virtual class during lockdown phase.

\section{Theoretical Premises of the Research}

Learning Theories for Online Education Just as no single learning theory has emerged for instruction in general, the same is true for online education. A number of theories have evolved related virtual learning. In this section, several theories have been examined in terms of their appropriateness for the online environment. 


\section{Community of Inquiry (CoI)}

The "Community of Inquiry (CoI)" model for online learning environments developed by Garrison, Anderson \& Archer (2000) is based on the concept of three distinct "presences": cognitive, social, and teaching. While recognizing the overlap and relationship among the three components, Anderson, et. al. (2001) advise further research on each component. Their model supports the design of online and blended courses as active learning environments or communities dependent on instructors and students sharing ideas, information, and opinions. Of particular note is that "presence" is a social phenomenon and manifests itself through interactions among students and instructors. The community of inquiry has become one of the more popular models for online and blended courses that are designed to be highly interactive among students and faculty using discussion boards, blogs, wikis, and videoconferencing (Garrison, et. al, 2000).

\section{Connectivism}

George Siemens (2004), one of the early MOOC pioneers, has been the main proponent of connectivism, a learning model that acknowledges major shifts in the way knowledge and information flows, grows, and changes because of vast data communications networks. Internet technology has moved learning from internal, individualistic activities to group, community, and even crowd activities. In developing the theory, Siemens acknowledged the work of Alberto Barabasi and the power of networks. He also referenced an article written by Karen Stephensen (1998) entitled "What Knowledge Tears Apart, Networks Make Whole," which accurately identified how large-scale networks become indispensable in helping people and organizations manage data and information. Siemens describes connectivism as: the integration of principles explored by chaos, network, and complexity and self-organization theories where learning is a process that occurs within nebulous environments of shifting core elements - not entirely under the control of the individual. Learning (defined as actionable knowledge) can reside outside of ourselves (within an organization or a database), is focused on connecting specialized information sets, and the connections that enable us to learn more and are more important than our current state of knowing" (Siemens, 2004).

\section{Theories and Frameworks for Online Education}

Seeking an Integrated Model 175 Siemens noted that connectivism as a theory is driven by the dynamic of information flow. Students need to understand, and be provided with, experiences in navigating and recognizing oceans of constantly shifting and evolving information. Siemens proposed eight principles of connectivism. Connectivism is particularly appropriate for courses with very high enrollments and where the learning goal or objective is to develop and create knowledge rather than to disseminate it. 1. Learning and knowledge rests in diversity of opinions. 2. Learning is a process of connecting specialized nodes or information sources. 3. Learning may reside in non-human appliances. 4. Capacity to know more is more critical than what is currently known. 5. Nurturing and maintaining connections is needed to facilitate continual learning. 6 . Ability to see 
connections between fields, ideas, and concepts is a core skill. 7. Currency (accurate, up-to-date knowledge) is the intent of all connectivist learning activities. 8. Decision making is itself a learning process. Choosing what to learn and the meaning of incoming information is seen through the lens of a shifting reality. While there is a right answer now, it may be wrong tomorrow due to alterations in the information climate affecting the decision.

Siemen's Eight Principles of Connectivism Online Collaborative Learning (OCL) Online collaborative learning (OCL) is a theory proposed by Linda Harasim that focuses on the facilities of the Internet to provide learning environments that foster collaboration and knowledge building. Harasim describes OCL as: a new theory of learning that focuses on collaborative learning, knowledge building, and Internet use as a means to reshape formal, non-formal, and informal education for the Knowledge Age" (Harasim, 2012, p. 81). Like Siemens, Harasim sees the benefits of moving teaching and learning to the Internet and largescale networked education. In some respects, Harasim utilizes Alberto Barabasi's position on the power of networks. In OCL, there exist three phases of knowledge construction through discourse in a group: 1. Idea generating: the brainstorming phase, where divergent thoughts are gathered 2. Idea organizing: the phase where ideas are compared, analyzed, and categorized through discussion and argument .Intellectual convergence: the phase where intellectual synthesis and consensus occurs, including agreeing to disagree, usually through an assignment, essay, or other joint piece of work (Harasim, 2012, p. 82). OCL also derives from social constructivism, since students are encouraged to collaboratively solve problems through discourse and where the teacher plays the role of facilitator as well as learning community member. This is a major aspect of OCL but also of other constructivist theories where the teacher is not necessarily separate and apart but rather, an active facilitator of, knowledge building. Because of the importance of the role of the teacher, OCL is not easy to scale up. Unlike connectivism, which is suited for largescale instruction, OCL is best situated in smaller instructional environments. This last issue becomes increasingly important when seeking commonality among online education theories.

\section{Methods and Materials}

This research adopted the quantitative research design. Quantitative research has been used to carry out the research. Both statistical tools and descriptive tools have been adopted to analyze and interpret the data collected. In this research, both primary and secondary sources have been used to collect the information. Primary sources of data of this study were the teachers who conducted the virtual class during COVID-19 lockdown phase of Bhojpur Multiple Campus, Bhojpur. Different books, journals, articles, newspapers, web sides, e-journal blogs, references were reviewed to collect secondary sources of information.

The population of this research was the teachers who conducted virtual class during COVID-19 lockdown phase in Bhojpur Multiple Campus, Bhojpur. 40 informants were sample size of this study.The study used non-random purposive 
sampling to choose the respondents. Purposive sampling is where the researcher will target certain group of people to be their respondents. For this study, the population was the teachers who took the classes of different subjects through virtual mode (Zoom, Microsoft Team, etc.) in Bhojpur Multiple Campus, during COVID-19 lockdown phase. The informants were given survey questionnaires and they were asked to give their answers. Semi structured interview was also used to collect the experiences of the teachers from two participants.

After preparing survey questionnaires, the researcher visited the Campus and met the informants selected by non-random purposive sampling method and built the rapport with the respondents. The researcher explained the purpose of the research and data elicited from the interview was recorded on audio-visual device.

Data collected of the study was analyzed and interpreted under the different headings and sub headings to make interpretation more vivid and stigmatic. The various facts and variables of the data have been presented in table, charts and diagrams with explanation. The analysis and interpretation of the data was made under different categories.

\section{Results and discussion}

In this section, data collected of the study has been analyzed and interpreted under the different headings and sub headings to make interpretation more vivid and stigmatic. The various facts and variables of the data have been presented in table, charts and diagrams with explanation. The analysis and interpretation of the data has been made under different categories. The main findings of the study have also been presented below by analyzing the data:

\section{Perception of the teachers of Bhojpur Multiple Campus towards virtual class during COVID-19 lockdown phase}

The perception of the teachers of BMC towards virtual class have been discussed and analyzed below on the basis of graph chart with explanation. The result of each statement has been shown in the graph with explanation.

\section{Q. How much do you agree or disagree on the following statements? Statement - 1}

Virtual class increases my anxiety, tension and fear over the class.

Strongly Disagree8\%

Disagree $20 \%$

Neutral20\%

Agree 52\%

StronglyAgree0\%

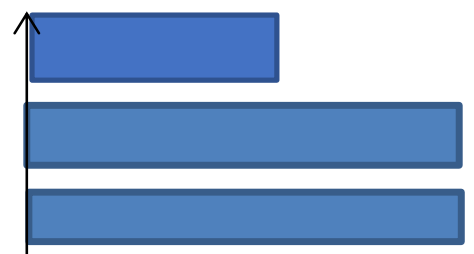


The bar graph above makes clear that over half of the teachers think that virtual class increases fear, anxiety and tension. $52 \%$ of the teachers agreed with this feeling. Most of them said that they felt anxiety due to the lack of enough knowledge and skill in using devices of internet and computer. We conclude that the teachers of the Bhojpur Multiple Campus do not have complete positive attitudes towards virtual learning during COVID-19 lockdown phase.

\section{Statement - 2}

In my view, virtual teaching is better than physical teaching.

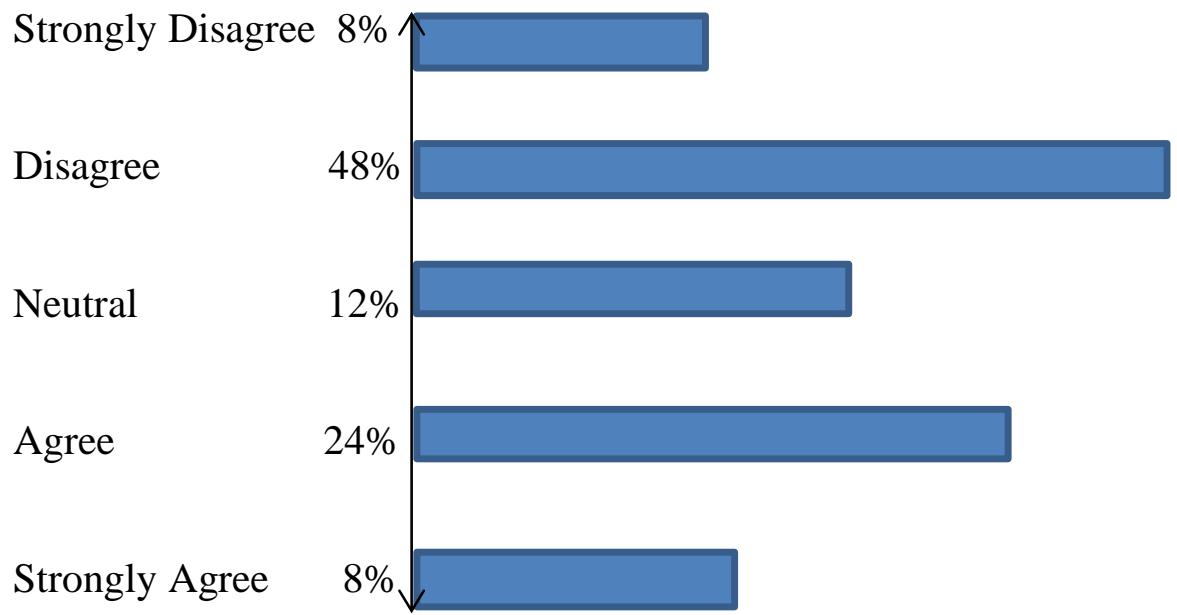

The graph shows that $48 \%$ of the teachers disagreed with physical class whereas only $24 \%$ of the teachers agreed with virtual teaching. It makes clear that the most of the teachers are not favor for virtual learning in Bhojpur Multiple Campus.

\section{Statement - 3}

I think the quality of virtual teaching is satisfactory because there will be more student's teacher interaction.

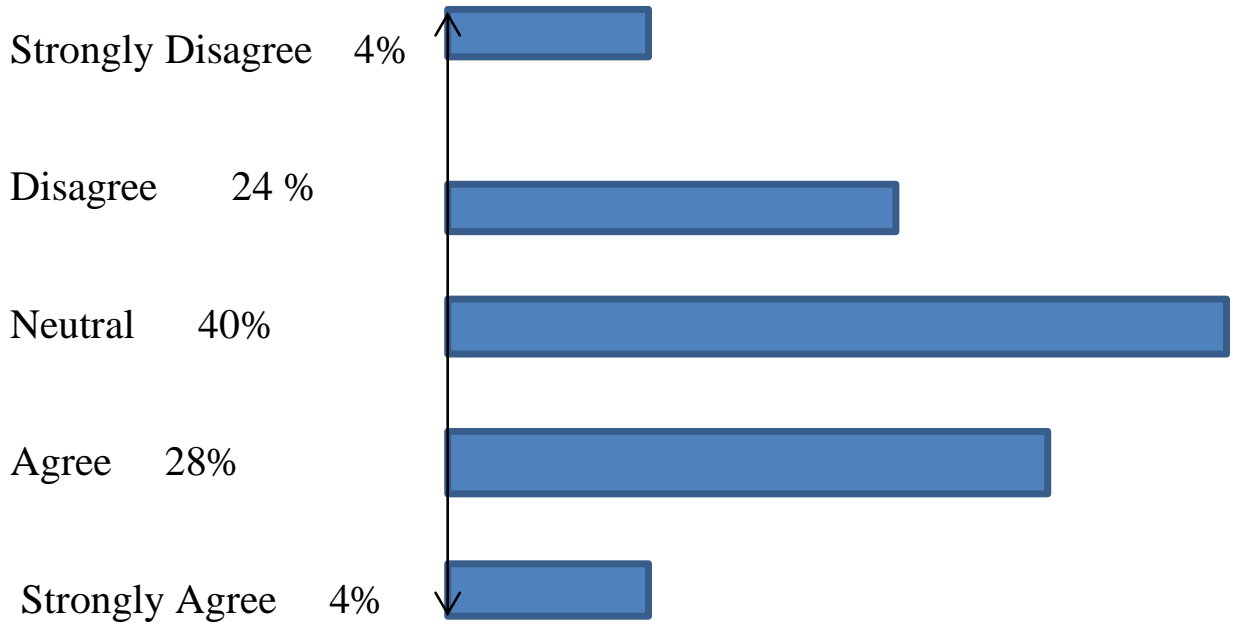


The graph tells that the teachers of BMC do not believe on virtual class regarding quality of education because there will be less interaction between the teachers and the students. Only $28 \%$ of the teachers showed their satisfactory on virtual class regarding their quality.

\section{Statement - 4}

Virtual teaching class is suitable solution during COVID-19 lockdown phase because it saves my time and effort.

Strongly Disagree $4 \%$

Disagree $8 \%$

Neutral $\quad 0 \%$

Agree $\quad 68 \%$

Strongly Agree $20 \%$

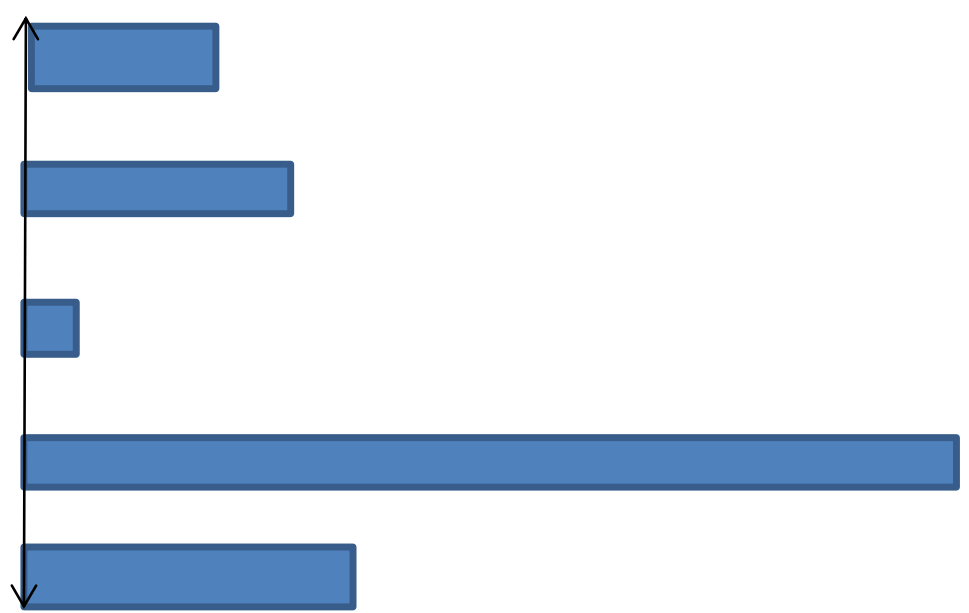

The graph displays that almost $68 \%$ of the teachers agreed with view that virtual teaching is a suitable solution for teaching and learning during COVID-19 lockdown phase.

\section{Statement - 5}

I enjoy virtual class than regular class. So, I prefer virtual class in normal situation.

Strongly Disagree $12 \%$

Disagree36 \%

Neutral $20 \%$

Agree $32 \%$

Strongly Agree $0 \%$

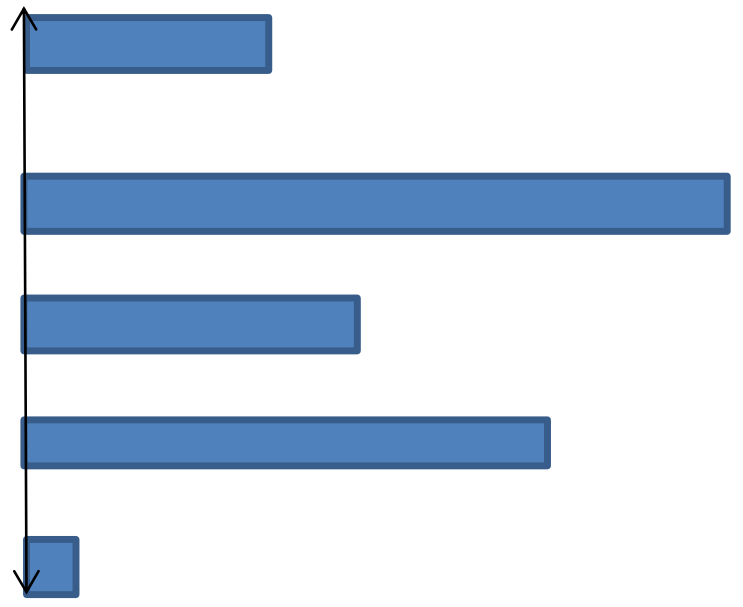


The graph makes clear that only $32 \%$ of the teachers enjoyed virtual teaching than physical class. So, majority of the teachers of BMC, did not prefer online class in normal situation.

\section{Statement - 6}

I prefer regular exam than virtual exam.

Strongly Disagree 4\%

Disagree $20 \%$

Neutral $16 \%$

Agree $40 \%$

Strongly Agree $20 \%$

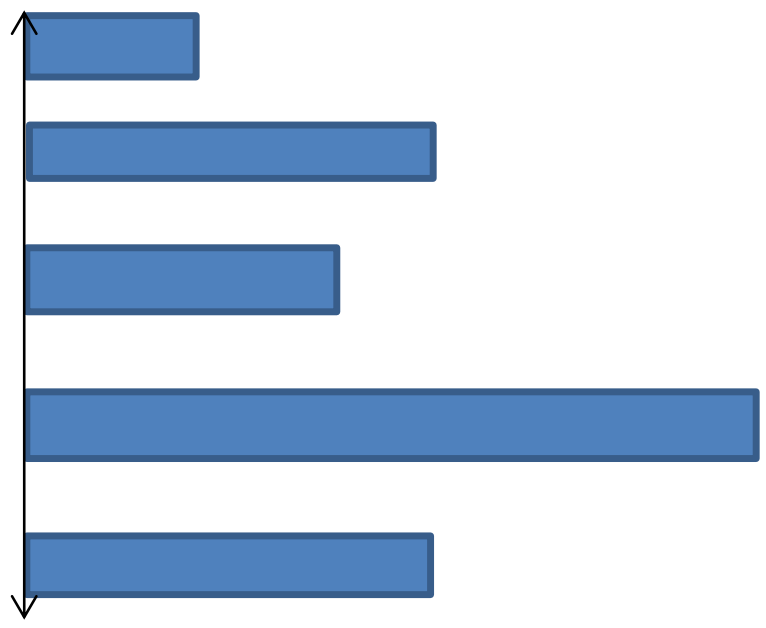

The graph says that $40 \%$ of the teachers liked regular exam than online exam. This clarifies that most of the teachers do not like virtual exam rather they like regular exam.

\section{Statement - 7}

I need training program to help me efficiently use virtual class.

Strongly Disagree $4 \%$

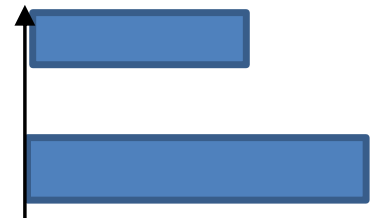

Disagree $16 \%$

Neutral $\quad 4 \%$

Agree $\quad 56 \%$

Strongly Agree

$20 \%$

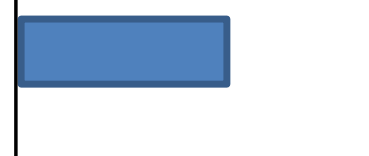

The graph indicates that majority of the teachers requires training in running virtual class because they do not have skill and knowledge in using technology and internet. 


\section{Obstacles that the teachers faced in virtual teaching during COVID-19 lockdown phase}

Which of the following listed difficulties did you face in your virtual class during COVID-19 lockdown phase?

I had to rely on help from others because I couldnot

cope with internet channels or work on computer.52\%

I did not have stable and speed internet.

I did not have laptop/desktop so I used only my smart Mobilephone. $40 \%$

I did not possess any device for virtual learning $32 \%$ I did not have internet access at all. $28 \%$

I did not have electricity or backup for stable electricity supply. $56 \%$

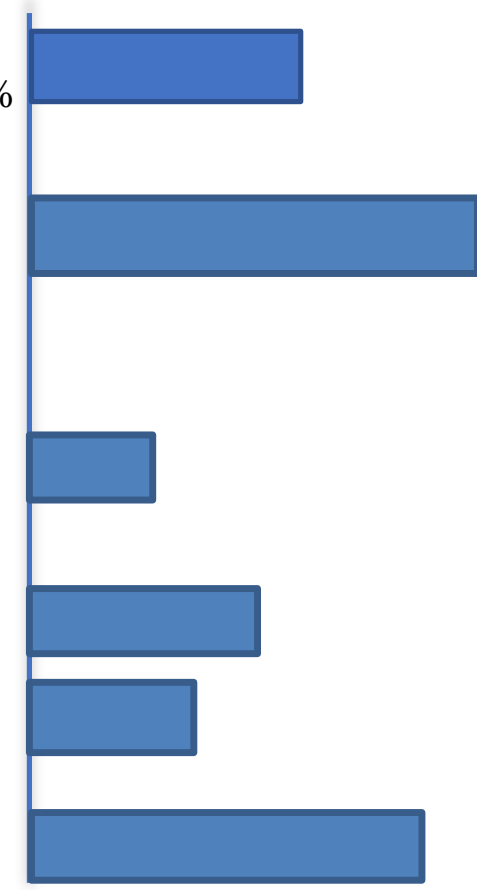

The graph above points out that more than half of the teachers had to rely on help from others because they could not cope with internet channels or work on computer. Almost $76 \%$ of the teachers of BMC did not have stable and speed internet. So, they faced obstacle on the virtual class created by slow and unstable internet during lockdown phase.40 \% of the teachers of BMC did not have their own laptop or computer. They had to rely on smart mobile phone for running virtual class with the students. $56 \%$ of the teachers of BMC did not possess backup for stable electricity support.

\section{Experience of the teachers on virtual class during COVID-19 lockdown phase}

The teachers felt wonderful experiences when they conducted virtual classes through Microsoft Team. They were not used to physical classes. They were not familiar with virtual classes. It was the first time that they had encountered with online class which was made possible by COVID-19 lockdown. Some experiences have been given below:

Researcher: What experience did you have in your virtual class during COVID-19 lockdown phase? Elaborate it based on your own feelings or experience.

Respondent (1) said,' in my experience, virtual learning is not only suitable during lockdown phase but also it is suitable for those students who are 
economically poor. The poor students can take the classes staying at their home without meeting the teachers in the real classroom. They need not to go city for higher education. In the city, they have to rent room. They have to afford money for transportation, room, food, etc., which they do not afford at home.'

Respondent (2) said, ' Online teaching is not good for me because it creates fear and tension before starting the class. I do not have enough knowledge and skill on computer and internet operation which brings fear in my mind. Another reason I do not like online teachings is that there will not be enough interaction between teachers and the students as in the physical class. Technical problems like unstable electric, internet, etc., disturb communication among the students and the teachers.'

In this section, the result of the study has been interpreted without recapitulating the theme of the study. Likewise, the result of the present study has also been compared with previous research findings. Moreover, the impact of the result has been discussed on the existing knowledge of the subject. At last, some suggestions have been made for further research to the researchers who wish to carry out research on this field.

\section{Perception of the teachers of Bhojpur Multiple Campus towards virtual class during COVID-19 lockdown phase}

Having analyzed the data, it can be said that the respondents do not like the virtual class during the lockdown phase because $52 \%$ respondents agreed that virtual class increases their anxiety, tension and fear over the class. Previous research on anxiety and stress in undergraduate university students has identified several persistent factors including "accommodation problems", "worry about the future", and "worry about examination success" (Uskun et al., 2008). There may be differences in average amounts of stress between males and females as previous studies have found females exhibited more stress than male undergraduate students (Cardoso et al. 2019). One interesting, but not surprising result of this study of increased anxiety felt by undergraduate students 262 Unger \& Meiran which participated in the survey, is confirmed by other recent studies which found increased anxiety during the COVID-19 pandemic to occur more often in people under the age of 35 (Huang \& Zhao, 2020).. In respondent's view, virtual teaching is not better than physical teaching because $56 \%$ respondents disagreed virtual learning whereas $32 \%$ respondents agreed virtual learning. This fact makes clear that respondents do not like virtual learning because they are used to physical class. Respondents think that the quality of virtual teaching is not satisfactory because only $32 \%$ respondents agreed with the satisfaction of virtual class whereas $28 \%$ teachers disagreed and $40 \%$ are neutral on this view.

Almost $68 \%$ of the teachers agreed with view that virtual teaching might be a suitable solution for teaching and learning during COVID-19 lockdown phase. However, only $32 \%$ of the teachers enjoyed virtual teaching than physical class. So, majority of the teachers of BMC did not prefer online class in normal situation. 
$60 \%$ of the teachers liked regular exam than online exam. This clarifies that most of the teachers do not like virtual exam rather they like regular exam. Majority of the teachers requires training in running virtual class because they do not have skill and knowledge in using technology and internet.

\section{Obstacles that the teachers faced in virtual teaching during COVID-19 lockdown phase}

Many teachers of BMC do not have knowledge and skills in information and communication technology (ICTs). As a result, 52\% teachers had to rely on help from others because they could not cope with internet channels or work on computer. Almost $76 \%$ of the teachers of BMC did not have stable and speed internet. So, they faced obstacle on the virtual class created by slow and unstable internet during lockdown phase. Likewise, $40 \%$ of the teachers of BMC did not have their own laptop or computer. They had to rely on smart mobile phone for running virtual class with the students. Similarly, $32 \%$ teachers did not possess any devices for virtual learning which is terrible for virtual class. $28 \%$ teachers did not have internet access at all.56\% the teachers of BMC did not possess backup for stable electricity support.

This study investigated the perception of the teachers towards virtual learning especially during Covid-19, can contribute as a substitute for the formal classroom learning environment in Bhojpur campus. Although there are many studies investigating students' perceptions regarding virtual learning, rarely any research scrutinized the teachers' perception regarding virtual learning, particularly in Nepal. Bhojpur campus needs more robust strategies and infrastructure to continue educational activities even during the crisis in the future.

The researcher used a brief sample which is a major limitation that further narrows down its scope. The researcher only investigated the attitude of the teachers towards virtual learning and it's obstacle of Bhojpur campus which is another limitation of the study. However, the researcher took every step to bring clarity in the methodology and data analysis process. Thus, the researcher recommends more studies concerning virtual learning for educational purposes in Nepal to cope with the existing challenges regarding virtual learning during pandemic.

\section{Conclusion}

During to Covid-19 outbreak, there is an increased dependency on virtual learning. People all around the world rely heavily on online platforms to communicate, entertain, and interact. Similarly, the educational system is also relying on online learning to pursue educational activities. Although, Bhojpur campus has a weak technological system and technology acceptance is slow, few teachers of campus emphasized on e-learning as a part of education. However, teachers can play a fundamental role in persuading the students for eLearning integration and adoption during the Covid-19 pandemic. At this point, it is essential to evaluate teachers' opinions regarding virtual learning. Due to specific limitations, the researcher could not gather a large sample of respondents; the study is still of 
greater relevance. Therefore, the researcher concludes that virtual learning can be a substitute for formal education, especially during emergencies like Covid19. By keeping the importance of eLearning during the current scenario (United Nations, 2020), the study also suggests effective policies to sustain technology adoption in Nepal.

Over half of the teachers think that virtual class increases fear, anxiety and tension. Most of them said that they felt anxiety due to the lack of enough knowledge and skill in using devices of internet and computer. We conclude that the teachers of the BMC do not have complete positive attitudes towards virtual learning during COVID-19 lockdown phase. Another important finding of this study is that majority of the teachers agreed with physical class whereas only minority of the teachers agreed with virtual teaching. It makes clear that the most of the teachers are not in favor of virtual learning in BMC. Next finding of the study is that there are some barriers of virtual learning which are personal, technical, logistical, and financial. To remove these barriers some modifications such as training, stable power and internet, infrastructures, electronic devices are required.

\section{References}

Adnan, M. (2020). Online learning amid the COVID-19 pandemic: Students perspectives. Journal of Pedagogical Research, 1(2), 45-51. https://doi.org/10.33902/jpsp.2020261309

Ali, S. (2019). Social Media Usage among Teenage Girls in Rawalpindi and Islamabad.The Electronic Journal on Information Systems in Developing Countries.18(1), 0-9.

Anderson, A., \&Grönlund, A. (2009). A conceptual framework for Online learning in developing countries: A critical review of research challenges. The Electronic Journal on Information Systems in Developing Countries.38(2), 1-16.

Bates, A. W. (1995).Technology, open learning and distance education, Rutledge.

Cardoso, J.V., Gomes, C.F.M., Pereira, R.J., \& Silva, D.A. (2019). Stress in university students: an epidemiological approach. Journal of Nursing UFPE On Line, 13, 1-6.

Dede, C (1997). Distributed learning: How new technologies promise a richer educational experience connection, New England's Journal of Higher Education and Economic Development, Vol. 12, Issue 2.

Figueiredo, A. M. De, Codina, A. D., Marculino, D. figueirredo, M, S., \& A Leon, C. (2020). Impact of lockdown on COVID-19 incidence and mortality in China: an interrupted time series study. Bull World Health Organ, April, 1-18. Retrieved from https://doi.org/http://dx.doi.org/10.2471/BLT.20.256701 
Garrison, D. R., Anderson, T., \& Archer, W. (2000). Critical inquiry in a textbased environment: Computer conferencing in higher education model. The Internet and Higher Education, 2(2-3), 87-105. Theories and Frameworks for Online Education: Seeking an Integrated Model

Habes, M. (2019). The influence of personal motivation on using social TV: A Uses and Gratifications Approach. International Journal of Information Technology and Language Studies, 3(1).

Harasim, L. (2012). Learning theory and online technologies. Routledge

Huang, Y., \& Zhao, N. (2020). Generalized anxiety disorder, depressive symptoms and sleep quality during COVID-19 outbreak in China: a webbased cross-sectional survey. Psychiatry Research, 20, 1-20.

International Labour Organization. (2020). ILO Sectoral Brief: COVID-19 and the Education Sector. March, 1-8.

Kirschner, P., Valcke, M. \&Slujsmans (1999). Design and Development of Third Generation Distance Learning Materials: From an Industrial Second Generation Approach Towards Realizing Third Generation Distance Education, in Akker, J.V., Branch, L.M., Gustafsm, J., Nieveen, N. \&Plonp. T. (eds) Design Approach and Tools in Education and Training. Kluwer Publishers.

Morris, R. 1997). Adaptive learning systems, National Institute of Standards and Technology, Retrieved form (http://www.atp.nist.gov/atp/97wp-It.htm.)

Muhaisen, O. Al, Habes, M., \&Alghizzawi, M. (2020).An Empirical Investigation the Use of Information, Communication Technologies to English Language Acquisition: A Case Study from the Jordan Technologies to English Language Acquisition: A Case Study From International Journal of Innovations in Engineering and Science, 7(5), 261-269.

Muhaisen, O. Al. (2020). An Empirical Investigation the Use of Information, Communication Technologies to English Language Acquisition : A Case Study from the Jordan Technologies To English Language Acquisition : A Case Study From. International Journal of Innovations in Engineering and Science, 7(5), 261-269.

Siemens, G. (2004). Connectivism: A learning theory for the digital age. Paper retrieved from: http://www.elearnspace.org/Articles/connectivism.htm

Stephenson, K., (1998). Internal Communication, No. 36: What Knowledge Tears Apart, Networks Make Whole. Retrieved from http://www.netform.com/html/icf.pdf

Sultan Alam. (2020). COVID 19: A Paradigm Shift in Education - PAMIR TIMES. 
UNESCO. (2006). Teachers and educational quality: Monitoring global needs for 2015. Retrieved November1, 2015 from

http://www.uis.unesco.org/template/pdf/Teachers2006/TeachersReport.

UNESCO.(2020a). School closures caused by Coronavirus (Covid-19).

UNESCO. (2020b). The Futures of Education after COVID-19 Regional Dialogue.

UNHCR. (2020). Supporting Continued Access to Education During Covid-19 Emerging Promising Practices.

Uskun, E. Kisioglu, A. N., \&Ozturk, M. (2008).Stress and its effects on depression and anxiety among undergraduates. Primary Care and Community Psychiatry, 13(2), 73-82.

United Nations Educational, Scientific and Cultural Organization.(2020). COVID19 Educational Disruption and Response .Retrieved from https://en.unesco.org/themes/education-emergencies/coronavirus-schoolclosures, Accessed 19th Mar 2020.Google Scholar

WHO.(2020a). Coronavirus disease 2019 (67).World Health Organization, 2019(March), 2633. https://doi.org/10.1001/jama.2020.2633

WHO.(2020b). Novel Coronavirus (2019-nCoV) Situation Report - 1.WHO Bulletin, JANUARY, 1-7.

Williams, M. J., Mayer, R., \& Minges, M. (2011).Africa's ICT infrastructure building on the mobile revolution.The World Bank.Retrieved November 1, 2015 from http://siteresources. worldbank.org/Information And Communication and Technologies/

Resources/AfricasICTInfrastructure_Building_on_MobileRevolution_201. pdf.PUTAJ - Humanities and Social Sciences $\square$ Vol.25, No.1-2 (Special Issue-Media Matters), 2017

Wu, J., Tsai, R. ay J., Chen, C. C., \& Wu, Y. (2006). An Integrative Model to Predict the Continuance Use of Electronic Learning Systems: Hints for Teaching. International Journal on E-Learning, 5(2), 287-302. 